\title{
Spontaneous cystogenesis of Toxoplasma gondii in feline epithelial cells in vitro
}

\author{
Renata M. de Muno ${ }^{1}$, Marcos A. Moura ${ }^{1}$, Luciany C. de Carvalho ${ }^{1}$, Sergio H. Seabra ${ }^{2}$ and Helene S. Barbosa ${ }^{1}$ \\ ${ }^{1}$ Laboratório de Biologia Estrutural, Instituto Oswaldo Cruz, Fundação Oswaldo Cruz, Rio de Janeiro, RJ, Brazil; \\ ${ }^{2}$ Laboratório de Tecnologia em Cultura de Células, Centro Universitário Estadual da Zona Oeste, RJ, Brazil
}

\begin{abstract}
Toxoplasma gondii Nicolle et Manceaux, 1908 is an obligate intracellular parasite with the ability to infect mammals and birds. The only definitive hosts for $T$. gondii are felids, as the parasites form immature oocysts that are shed in the faeces. Here we introduce cat cells as a model for the study of experimental toxoplasmosis. We selected epithelial cells derived from cat kidneys (CRFK) as a target to determine the intracellular fate of bradyzoites of the T. gondii ME49 strain. In parallel, we compared this infection using epithelial cells from the rat intestine (IEC-6), considering the enteroepithelial development that occurs in the cat. Different ratios of parasites to host cells were assayed over the course of a 14-day-infection. The intracellular development of $T$. gondii was dependent on the source of the epithelial cells and also on the parasite/host cell ratio. Cystogenesis was well established in the CRFK cell line at a ratio of $1: 10$ after 10-14 days of infection. This cellular model system opens a new field of investigation into the molecular aspects of the interactions between $T$. gondii and feline epithelial cells. The CRFK cell line appears to be a potential cellular model for large scale cyst production in vitro, which would allow a reduction in the number of animals used and/or replacement of animals by in vitro cultures.
\end{abstract}

Keywords: bradyzoites, felids cells, tachyzoites, tissue cysts in vitro, toxoplasmosis

Toxoplasma gondii Nicolle et Manceaux, 1908, an intracellular apicomplexan parasite, infects different species of mammals and birds (Dubey 1998). Asexual reproduction of the parasite takes place in these animals, which serve as intermediate hosts (Black and Boothroyd 2000, Lehman et al. 2000). Cats and other felids are the only hosts that directly spread $T$. gondii in the environment and are responsible for the enteroepithelial stage of the parasite (Dubey et al. 2004). These animals are considered definitive hosts and the processes of schizogony, gametogony and sporogony take place in their intestinal epithelia, resulting in the formation of immature oocysts that are eliminated with their faeces (Dubey and Frenkel 1972, 1973, Dubey 1973, Dubey et al. 1998). The mechanisms by which the enteroepithelial cycle in felids is induced are still unknown.

The morphological characterization of the coccidian cycle of $T$. gondii in the gut of neonatal cats has been undertaken in in vivo systems (Dubey and Frenkel 1972, Ferguson et al. 1974, 1975, Speer and Dubey 2005, Ferguson 2009), and several molecular aspects of this process have been explored (Ferguson 2004). Due to the difficulty of using cat as an experimental model, these studies have not progressed very far, and alternative models will have to be introduced to facilitate further investigations.
Recently, our group has developed a protocol for obtaining feline enterocytes from primary cultures and their subsequent maintenance (Moura et al. 2009). This system provides a potential alternative approach for the study of T. gondii-host cell interactions. Our initial studies found intracellular parasites that were very similar to the schizonts of $T$. gondii that have been described in vivo. This first step opened up the possibility that the enteroepithelial development of $T$. gondii could also be explored in vitro.

Feline intestinal cell lines in cell banks are absent and there are only two felid epithelial cells lines: AK-D liver epithelium (Cantin and Woods 1930) and renal feline kidney cells (CRFK line) (Crandell et al. 1973). Intestinal epithelial cells lines, such as the IEC-6 isolated from rats, are alternative cellular models for parasite life cycle studies, and they can be employed for comparisons with the feline epithelial CRFK cells. The morphological aspects of the bradyzoite-host cell interactions and the use of epithelial cells from different sources may provide a basis for a better understanding of the intracellular development of $T$. gondii in these cells. We are pioneering the use of cat cells, specifically the CRFK cell line, to study its interaction with bradyzoites of $T$. gondii. The introduction of this cell line has the potential to contribute new insights into our understanding of the cell biology of Toxoplasma.

Address for correspondence: H.S. Barbosa, Laboratório de Biologia Estrutural, Instituto Oswaldo Cruz, Fundação Oswaldo Cruz, Av. Brasil 4365, Rio de Janeiro, RJ, 21040-361, Brazil. Phone: 005521 25621026; E-mail: helene@ioc.fiocruz.br 


\section{MATERIALS AND METHODS}

The experiments were carried out in accordance with the guidelines established by the Fundação Oswaldo Cruz, Committee of Ethics for the Use of Animals, resolution 242/99, by license CEUA LW 10/10, and by the Guidelines on the Care and Use of Animals for Experimental Purposes and Infectious Agents (NACLAR).

\section{Epithelial cell lines}

CRFK from normal epithelial tissue from the renal cortex of Felis catus Linnaeus, 1758 (domestic cat) (BCRJ N ${ }^{\circ}$ CR0268) and IEC-6 from normal epithelial tissue from the intestines of rats (BCRJ N ${ }^{\circ} \mathrm{AP} 003$ ) were used. The cells were acquired from the Rio de Janeiro Cell Bank (http://www.bcrj.hucff.ufrj.br).

CRFK and IEC- 6 were plated at a concentration of $1.0 \times$ $10^{5}$ cells $/ \mathrm{ml}$ in $25 \mathrm{~cm}^{3}$ bottles (Gibco BRL, Paisley, UK) in DMEM/Hams F12 medium (1: 1) (Sigma-Aldrich, St. Louis, USA) containing a $1 \%$ antibiotic solution (Sigma-Aldrich) and $10 \%$ bovine fetal serum. The cells were incubated at $37^{\circ} \mathrm{C}$ in a $5 \% \mathrm{CO}_{2}$ atmosphere. Every two days, half of the medium was discarded and the same volume of fresh medium was added. The cells were cultivated until they reached approximately $80 \%$ confluence. At this point, the cells were treated for $10 \mathrm{~min}$ at $37^{\circ} \mathrm{C}$ with dissociation solution (PBS with $0.01 \%$ EDTA and $0.25 \%$ trypsin). After dissociation, the cells were placed in culture medium at $4{ }^{\circ} \mathrm{C}$ with $10 \%$ bovine fetal serum to inhibit the action of trypsin, centrifuged for $7 \mathrm{~min}$ at $650 \mathrm{~g}$ at $4{ }^{\circ} \mathrm{C}$ and grown in 24 -well plates on coverslips $\left(8 \times 10^{4}\right.$ cells/well $)$.

\section{Isolation of tissue cysts and bradyzoites}

Toxoplasma gondii cysts from the ME-49 strain (Type II) were inoculated intraperitoneally into C57BL/6 female mice (15-18 g) with 50 cysts/animal. After 4 and 12 weeks post-infection, the mice were sacrificed and the brain cysts were isolated as described previously (Freyre 1995, Popiel et al. 1996; Guimarães et al. 2007, 2008). Bradyzoites were obtained from the isolated tissue cysts (Guimarães et al. 2008).

\section{Interaction of $T$. gondii-epithelial cell lines}

Confluent CRFK and IEC-6 cultures were infected with $T$. gondii bradyzoites. The assays were performed at ratios of $1: 5,1: 10$ or $1: 20$ (parasite-host cell) for periods ranging from 1 to 4 days to analyse the course of infection and also to evaluate the parasites' intracellular fate. After the interaction periods, the cells were washed in PBS and further processed for subsequent experiments. The ability of $T$. gondii bradyzoites to infect host cells in vitro was analysed after fixation in Bouin's solution and Giemsa staining. The percentual of infection was quantified after 24-96 h using 400 cells per coverslip, in three independent experiments, each one performed in duplicate and analysed by two independent observers. The analysis was performed using an Axioplan 2 Zeiss microscope. The quantitative data were expressed as the mean \pm standard error and the results were statistically analysed using the Student-Newman-Keuls test. The differences were considered statistically significant when the $\mathrm{p}$ values were $<0.05$.

\section{Characterization of $\boldsymbol{T}$. gondii stages by immunolabeling}

CRFK cells infected with $T$. gondii bradyzoites (1:10 parasite-host cell ratio) were used for this analysis. The differentiation of intracellular parasites was monitored using stage-specific antibodies and lectin. Tachyzoites were identified by immunostaining with anti-SAG-1 antibodies and cysts of $T$. gondii were identified with lectin DBA conjugated to TRITC (SigmaAldrich, L6533), which binds to $\mathrm{N}$-acetyl-galactosamine groups (Zhang et al. 2001). Initially, the cultures were fixed with $4 \%$ PFA in PBS for 10 min at $4{ }^{\circ} \mathrm{C}$ on different days $(1-4,6,10,11$ and 13), washed three times for $10 \mathrm{~min}$ in PBS and then, were incubated for $30 \mathrm{~min}$ in $50 \mathrm{mM}$ ammonium chloride to block free aldehyde radicals.

After these steps, the cells were permeabilized for $20 \mathrm{~min}$ with a PBS solution containing $0.05 \%$ Triton X-100 (Roche, Rio de Janeiro, Brazil) and 4\% BSA (Sigma-Aldrich) to block nonspecific binding.

For the indirect immunofluorescence assays, the host cells were incubated for $2 \mathrm{~h}$ at $37^{\circ} \mathrm{C}$ with an anti-SAG-1 primary antibody diluted $1: 200$ in PBS/BSA. After this incubation, the cells were washed with PBS containing 4\% BSA and incubated for $1 \mathrm{~h}$ at $37^{\circ} \mathrm{C}$ with the secondary antibody at a dilution of $1: 1000$ (anti-mouse IgG conjugated with FITC-F5262).

For direct fluorescence, the cells were incubated for $1 \mathrm{~h}$ at room temperature with DBA lectin-TRITC (1: 200 dilution) in PBS. Next, the cultures were washed 3 times for $10 \mathrm{~min}$ in PBS, incubated for $5 \mathrm{~min}$ in $0.1 \mu \mathrm{g} / \mathrm{mL}$ with 4',6-diamidino2-phenylindole (DAPI, which intercalates in DNA, SigmaAldrich) and diluted 1:10000 in PBS. After the PBS wash, the coverslips were mounted on slides with a solution of $2.5 \%$ DABCO (1,4-diazabicyclo-[2,2,2]-octane-triethylenediamine, antifading, Sigma-Aldrich) in PBS containing 50\% glycerol, $\mathrm{pH}$ 7.2. Controls were performed by omission of the primary antibody, and for DBA, a competitive reaction with the addition of $50 \mathrm{mM}$ $\mathrm{N}$-acetyl-galactosamine (GalNAc) was carried out.

The samples were examined with a confocal laser-scanning microscope (CLSM Axiovert 510, META, Zeiss, Germany) using a 543 Helium laser (LP560 filter), 488 Argon/Krypton laser (Ar/Kr) (filter LP515) and a 405 Diiod laser (LP 420 filter). The analysis of the cystogenesis establishment was carried out monitoring a total of 100 infected cells per coverslip of three independent experiments, in duplicate, at interaction times of $24 \mathrm{~h}$ to 13 days using a Zeiss microscope Axio Imager A2. This methodology is based on labeling of infected cells with DBA, which has high affinity for cyst wall protein.

\section{Ultrastructural analysis}

For ultrastructural studies, CRFK cell cultures infected with T. gondii bradyzoites (1:10 parasite-host cell ratio) were used. This parasite-host cell ratio increased the incidence of intracellular cysts in vitro as demonstrated by kinetic studies. Both the cells and supernatants obtained from 3 to 14 days of infection were washed 3 times for 10 min with PBS and fixed for $1 \mathrm{~h}$ at $4{ }^{\circ} \mathrm{C}$ in $2.5 \%$ glutaraldehyde diluted in a $0.1 \mathrm{M}$ sodium cacodylate buffer containing $3.5 \%$ sucrose and $2.5 \mathrm{mM} \mathrm{CaCl}_{2}$ (pH 7.2). After fixation, the cells were washed in the same buffer and then post-fixed for $30 \mathrm{~min}$ at room temperature in $1 \%$ osmium tetroxide diluted in a $0.1 \mathrm{M}$ cacodylate buffer.

For transmission electron microscopy (TEM) analysis, the cells were washed in the same buffer, scraped from the plastic dish at $4{ }^{\circ} \mathrm{C}$ and centrifuged for $5 \mathrm{~min}$ at $10000 \mathrm{~g}$. The cells were then dehydrated in graded acetone and embedded in an epoxy resin (PolyBed 812). Thin sections were stained with uranyl acetate and lead citrate and then examined under a transmission electron microscope (Jeol JEM1011).

For scanning electron microscopy (SEM), the infected cell cultures were fixed for $30 \mathrm{~min}$ at room temperature with $2.5 \%$ 
glutaraldehyde in $0.1 \mathrm{M} \mathrm{Na}$-cacodylate buffer ( $\mathrm{pH}$ 7.2) and postfixed for $30 \mathrm{~min}$ at room temperature with a solution of $1 \% \mathrm{OsO}_{4}$ containing $2.5 \mathrm{mM} \mathrm{CaCl}_{2}$ in the same buffer. The cells were dehydrated in an ascending acetone series and dried by the critical point method with $\mathrm{CO}_{2}$ (CPD 030, Balzers, Liechtenstein, Switzerland). The monolayer was gently scraped with scotch tape (Flood 1975) to expose the cytoplasmic face of the cells. The scraped portion of the cells, which remained adhered to the tape, was also observed. The samples were mounted on aluminum stubs, coated with a $20 \mathrm{~nm}$ layer of gold and examined in Jeol JSM6390LV and JSM 6490LV scanning electron microscopes (Tokyo, Japan). The samples were analysed at the Electron Microscopy Platform of the Instituto Oswaldo Cruz and Centro Universitário Estadual da Zona Oeste.

\section{RESULTS}

\section{Infection of IEC-6 and CRFK cells with Toxoplasma gondii bradyzoites of the ME-49 strain}

Quantitative analysis of the interaction between $T$. gondii bradyzoites (ME49) and IEC-6 cells using an infective load of $1: 5$ (parasite-cell) showed that the average number of infected IEC- 6 cells remained almost constant until $72 \mathrm{~h}$ post-infection. After this period, there was a slight decline in the number of infected cells. In contrast, analysis of the CRFK line showed an increase in the average number of infected cells, especially after $48 \mathrm{~h}$ of infection (Table 1).

Quantitative analysis of T. gondii bradyzoites in IEC-6 and CRFK cultures using lower infective loads (parasitecell ratios of $1: 10$ and $1: 20$ ) also showed statistically significant $(\mathrm{p} \leq 0.05)$ differences between the infections of host cells (Table 1). The kinetic study of IEC-6 cells during $48 \mathrm{~h}$ of infection showed several parasitophorous vacuoles per cell with only one parasite inside (Fig. 1A). After $72 \mathrm{~h}$ of infection, several cells contained intracel-

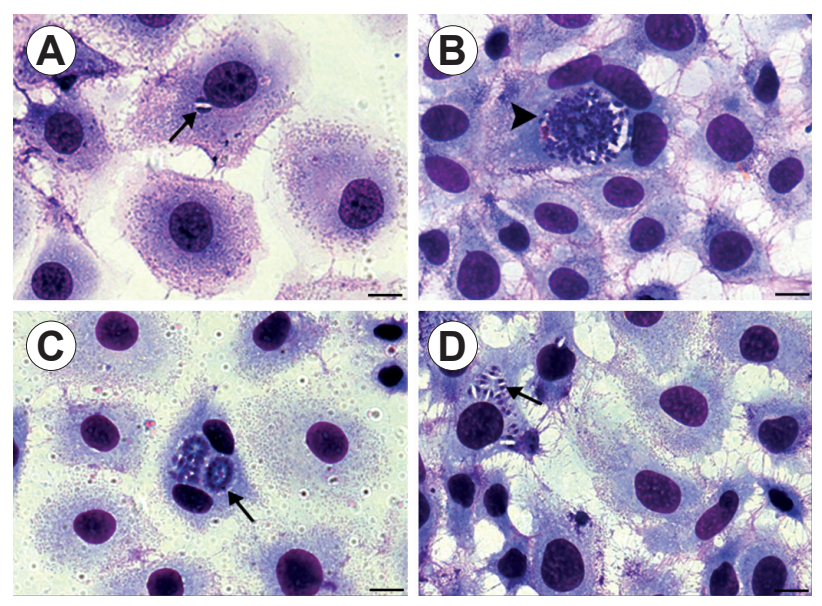

Fig. 1. IEC-6 cell culture infected with Toxoplasma gondii bradyzoites of the ME49 strain. A - cells with parasitophorous vacuoles (PV) containing few parasite in each PVs at $48 \mathrm{~h}$ of infection (arrow). B, C - after 72 h, 'cyst-like' structures were observed (arrowhead), but most of the structures were rosettes as seen in C (arrow). D - after $96 \mathrm{~h}$, parasites were observed in couples inside the same cell (arrow). Scale bars $=20 \mu \mathrm{m}$. lular cyst-like structures (Fig. 1B), but the presence of rosettes among infected cells during the same period was more frequent (Fig. 1C). After 96 h, several cells showed vacuoles containing only one parasite in a panel of only a few infected cells, as illustrated in Figure 1D.

Table 1. Mean of proportion (in \%) of IEC-6 and CRFK infected with Toxoplasma gondii bradyzoites of the ME-49 strain using different infection ratios.

\begin{tabular}{cccccc}
\hline \multirow{2}{*}{$\begin{array}{c}\text { Infection } \\
\text { ratio }\end{array}$} & Cell line & \multicolumn{4}{c}{ Hours post infection } \\
\cline { 2 - 6 } $1: 5$ & IEC-6 & $10.5 \pm 3.2^{\mathrm{a}}$ & $12.7 \pm 6.9^{\mathrm{a}}$ & $14.8 \pm 2.8^{\mathrm{a}}$ & $8.8 \pm 5.4^{\mathrm{a}}$ \\
& CRFK & $12.8 \pm 3.5^{\mathrm{a}}$ & $23.2 \pm 4^{\mathrm{a} *}$ & $55.8 \pm 11.8^{\mathrm{a} *}$ & $84.2 \pm 31.3^{\mathrm{a} *}$ \\
\multirow{2}{*}{$1: 10$} & IEC-6 & $4.8 \pm 0.75^{\mathrm{a}}$ & $11.2 \pm 6^{\mathrm{a}}$ & $9.8 \pm 1.94^{\mathrm{a}}$ & $12.7 \pm 5.2^{\mathrm{a}}$ \\
& CRFK & $6.3 \pm 1.2^{\mathrm{a}}$ & $17.3 \pm 10^{\mathrm{a} *}$ & $55.3 \pm 4.5^{\mathrm{a} *}$ & $68.7 \pm 13^{\mathrm{a} *}$ \\
$1: 20$ & IEC-6 & $6.9 \pm 13^{\mathrm{a}}$ & $7.0 \pm 2.1^{\mathrm{a}}$ & $8.2 \pm 4.3^{\mathrm{a}}$ & $9.6 \pm 2.1^{\mathrm{a}}$ \\
& CRFK & $0.8 \pm 0.5^{\text {a* }}$ & $2.8 \pm 1.7^{\mathrm{a} *}$ & $14.8 \pm 4.2^{\mathrm{a} *}$ & $33.5 \pm 3.4^{\mathrm{a} *}$ \\
\hline
\end{tabular}

${ }^{\mathrm{a}}$ mean \pm SD of at least three independent experiments; * significant dif-

ference $(p<0.05)$ between IEC- 6 and CRFK at the same conditions.

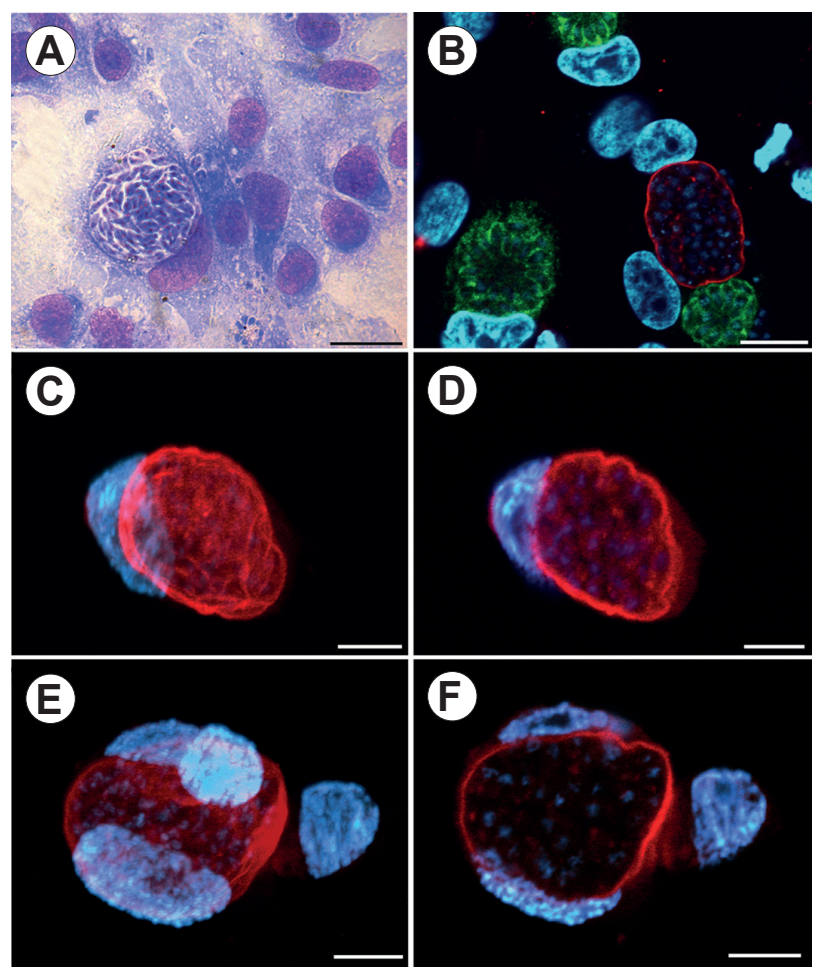

Fig. 2. Interaction of Toxoplasma gondii ME49 bradyzoites and CRFK cells at an infection ratio of $1: 10$ (parasite-host cell). A - formation of cystic structures 96 hpi stained with Giemsa and a few parasites in neighbouring cells; $\mathbf{B}$ - presence of T. gondii cysts revealed by lectin DBA-TRITC; the nuclei of parasites are in blue due to the DAPI stain and tachyzoites are in green as revealed by the anti-SAG-1 antibody; $\mathbf{C}-\mathbf{F}$ - cysts of T. gondii in CRFK cells after 13 days of infection; reconstruction and sectioning of the same cyst revealed by TRITC-DBA lectin clearly showing the cyst wall and the nuclei of the parasites in blue (C,D); reconstruction and sectioning of other cysts revealed by TRITC-DBA lectin and the nuclei of parasites and the nuclei of the host cells in blue (E,F). Scale bars: $A=20 \mu \mathrm{m}$; $\mathrm{B}=10 \mu \mathrm{m} ; \mathrm{C}-\mathrm{F}=5 \mu \mathrm{m}$. 

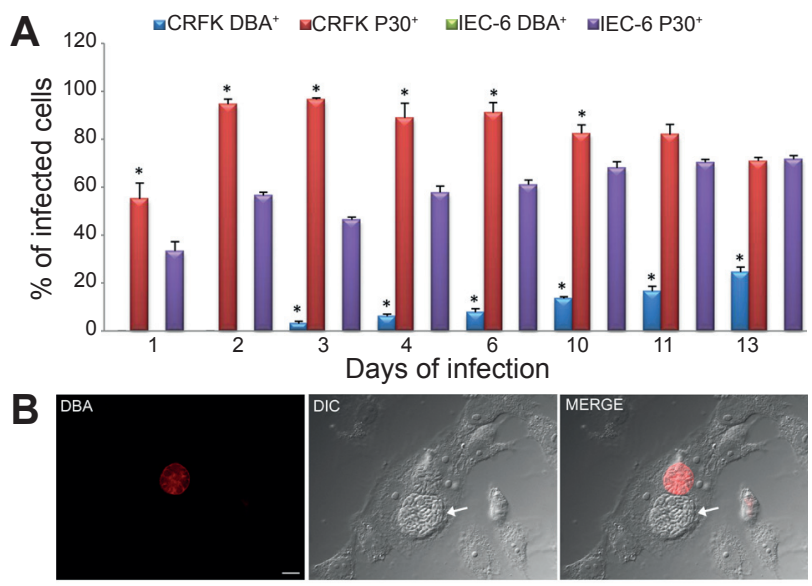

C
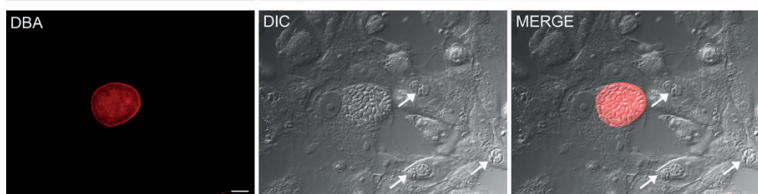

D

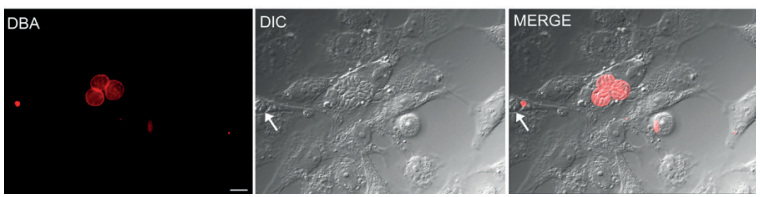

Fig. 3. Toxoplasma gondii cysts from 1 to 13 days post infection. A - percentage of infected CRFK and IEC- 6 cells $\mathrm{DBA}^{+}$and $\mathrm{P} 30^{+}$; asterisks indicate significant difference $(\mathrm{p}<0.05)$ between IEC-6 and CRFK at same conditions; B-D - cysts of $T$. gondii were confirmed in CRFK by DBA ${ }^{+}$staining. Scale bars $=10 \mu \mathrm{m}$.

At an even lower infective load (1 : 20 parasite-cell ratio), the average number of infected IEC- 6 cells was lower than the average observed with CRFK after $72 \mathrm{~h}$ (Table 1). The analysis of the CRFK line, unlike the IEC6 cells, showed a trend of increasing infection during the periods analysed, demonstrating that the differences in susceptibility between these cell lines were independent of the parasite-cell ratio used.

During the analysis of bradyzoite infectivity in CRFK and IEC-6 cells, parasitic structures similar to $T$. gondii cysts were observed. The CRFK cell line produced more cyst-like structures than the IEC-6 cell line, especially after $72 \mathrm{~h}$ of infection (Fig. 2A).

\section{Cystogenesis in CRFK cultures}

Assays for the detection of cysts in CRFK and IEC6 lines were performed by incubation with the lectin DBA-TRICT. CRFK line demonstrated cystogenesis after $72 \mathrm{~h}$ of infection with bradyzoites at a ratio of $1: 10$ (Figs. 2B-F, 3A). Tachyzoites were identified using an anti-SAG-1 primary antibody. There was a high incidence of cells that had established the lytic cycle and of parasites that had undergone conversion from bradyzoite to tachyzoite (Fig. 3A). The presence of cells containing cysts was spontaneous and was independent of chemical or physical maneuvers that induced cystogenesis. In

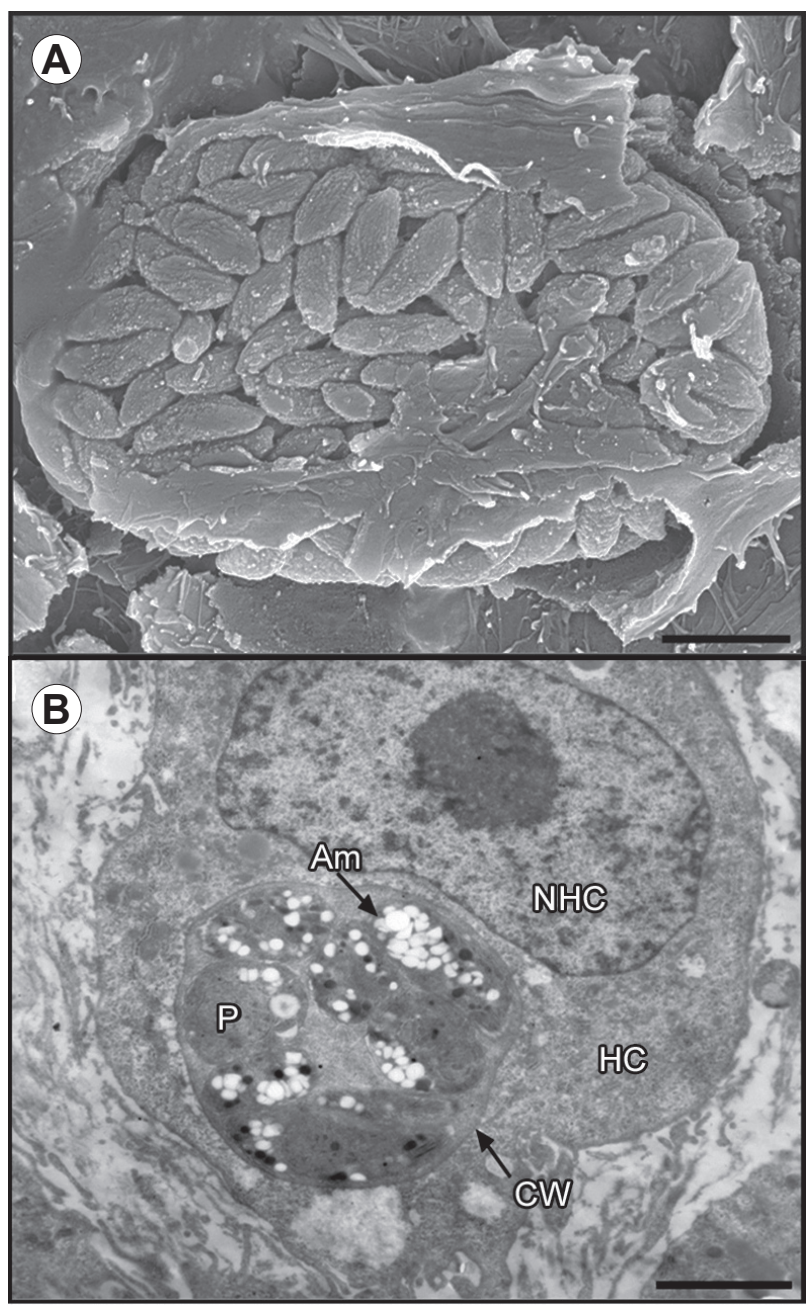

Fig. 4. Cysts of Toxoplasma gondii in CRFK cells at 13 days post infection. A - intravacuolar structures of various sizes containing parasites with overlapping features such as cysts. $\mathbf{B}-\mathrm{Cyst}$ (CW) near the nuclei of host cell (NHC) containing parasites (P) with a large number of amylopectin granules (Am). Scale bars: $\mathrm{A}=5 \mu \mathrm{m} ; \mathrm{B}=1 \mu \mathrm{m}$.

11-day-old cultures, incubation with the P30 antibody revealed infected cells containing cysts, and some were filled with tachyzoites arranged as rosettes (Fig. 2B). Figure $3 \mathrm{~B}-\mathrm{D}$ illustrates the cystogenesis of $T$. gondii maintained for 13 days, showing CRFK line containing one or more cysts.

\section{Ultrastructural characterization of cystogenesis in CRFK cells}

CRFK cultures were processed for SEM and scraped with scotch tape after 13 days of infection. These cells showed intravacuolar structures of various sizes, which contained parasites with overlapping features, such as cysts, indicating that $T$. gondii cystogenesis had spontaneously established itself (Fig. 4A). These structures presented several characteristics similar to cysts, such as the membrane modification forming the cystic wall and 


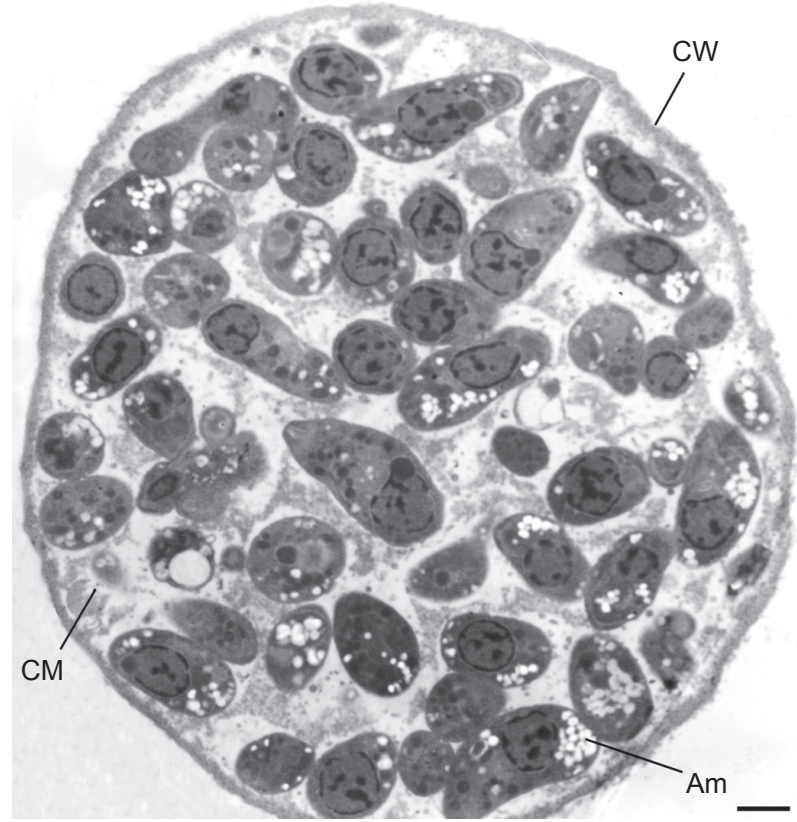

Fig. 5. A cyst of Toxoplasma gondii released into the supernatant culture after 14 days of infection. Abbreviations: Am - amylopectin granules; CM - cystic matrix; CW - cyst wall. Scale bar $=1 \mu \mathrm{m}$.

the high electron density of the cystic matrix. Intracystic parasites presented a large amount of amylopectin granules (Fig. 4B).

After 14 days of infection, we were able to identify T. gondii cysts containing several parasites with a large quantity of amylopectin granules, characteristic of the bradyzoite forms, and a thick electron-dense cyst wall (Fig. 5).

\section{DISCUSSION}

This article presents two findings with respect to the Toxoplasma gondii-host cell interaction: the use of a feline cell lineage and of bradyzoite forms. The rationale for utilizing bradyzoites as the source of infection of CRFK and IEC- 6 lines is that the natural route of transmission of $T$. gondii occurs through the consumption of raw meat contaminated with cysts. Studies using in vitro bradyzoite infections are not often used, likely because the isolation and purification involve a long process and require a reasonably large number of animals.

The difficulty in reproducing the in vivo morphological characterization of the enteric cycle of $T$. gondii in vitro requires continued euthanasia of cats (today prohibited; see Ferguson 2009 for review). New laws imposed to protect animals have led to the search for alternative models.

Most of the in vitro studies examining tachyzoitebradyzoite conversion in cell lines were developed because of the ease of cell growth and their long survival time in monolayers. However, the cell type where cystogenesis occurs in vivo has not been considered in this choice (Lindsay et al. 1991, McHugh et al. 1993). Recently, our group employed skeletal muscle cells to target the establishment of cystogenesis in vivo, and our data strongly suggested that factors inherent in the cell type may be crucial for cyst formation (Ferreira da Silva et al. 2008, 2009a,b).

When bradyzoite forms were used as a source of infection for CRFK and IEC-6, the CRFK line was statistically more susceptible to infection by the bradyzoites than the IEC-6 line suggesting that this characteristic may be a function of the properties of an intestinal cell once these cells produce pro-inflammatory cytokines.

Dubey (2006) compared the infectivity of oocysts and bradyzoites in cats in vivo using different dosages of the parasite stages. The results showed that bradyzoites were more infective than oocysts regardless of the dose, demonstrating that infection was stage-dependent. That study also showed that bradyzoites were more pathogenic for cats than for mice, suggesting that both the infective stage and the intermediate host are determinants of the pathogenicity of $T$. gondii.

Our results using bradyzoites as the source of infection have shown that feline cells are more susceptible to infection than rat cells, and they induce spontaneous cystogenesis in vitro after 72 hours of infection. These results suggest that the fate of intracellular parasites may be modulated by the infective stage such as bradyzoites, and also by the host cell, in this case feline cells.

In addition, the formation of these cystic structures in vitro was dependent not only on the parasite strain and cell type but also on the infection load used. Previous studies using primary cultures of feline enterocytes infected with bradyzoites of the ME49 strain in vitro revealed that these cells were more susceptible to infection than the CRFK and IEC- 6 cell lines, and enterocytes also showed a larger number of cystic forms when infected at a parasite-cell ratio of $1: 10$ (Moura et al. 2009). These data can be further explained by the molecular and physiological characteristics of the preserved tissue in vivo.

After 10 days of infection in CRKF cells, T. gondii cysts were identified by lectin DBA staining, which binds specifically to the sugar $\mathrm{N}$-acetyl-D-galactosamine present in the cyst wall, as previously demonstrated by Matsubayashi and Akao (1963), Weiss and Kim (2000) and Dzierszinski et al. (2004). In addition, Toxoplasma stage differentiation is largely viewed as a stress-related response to environmental conditions, such as exogenous stress factors, i.e. alkaline $\mathrm{pH}$, IFN- $\gamma$ and other proinflammatory cytokines, chemicals or drugs, heat shock and deprivation of nutrients (reviewed in Ferreira da Silva et al. 2008).

In contrast, some authors consider spontaneous cystogenesis to be dependent on the strain of $T$. gondii and propose that avirulent strains, such as ME49, possess the ability to form cysts naturally in mammalian cell cultures (Darde et al. 1989, Lindsay et al. 1991, McHugh et al. 
1993, Fischer et al. 1997, Ferreira da Silva et al. 2009a,b). This question has not been fully clarified. In a recent paper, we reviewed data on $T$. gondii-skeletal muscle cell interactions and presented compelling data suggesting that the cell type is one of the factors determining the fate of the intracellular parasite (Ferreira da Silva et al. 2008).

Toxoplasma gondii cysts were also seen by transmission electron microscopy, and the presence of cysts was confirmed by the observation of parasites containing large numbers of amylopectin granules and a high electron-dense membrane surrounding the parasites. These structures were similar to those involved in the formation of a cyst wall, especially after 10 days of infection. However, different results can be found in the literature, ranging from 6-7 days (Shimada et al. 1974, Hoff et al. 1977), 20-21 days (Hogan et al. 1960) or up to 40-80 days as described by Jones et al. (1986), depending on the method used to evaluate the kinetics of in vitro cystogenesis.

These differences may be related to the virulence of the strains and the infective stage of the parasite used in the experiments. The rate of conversion between the infective stages and the quantity of cysts generated in vitro have been related to the strain of $T$. gondii - McHugh et al. (1993), Soête et al. (1994). The low virulence strains that are more efficient in cyst formation in mice, such as the ME-49 strain, have a higher rate of cyst formation in culture than the high virulence strains, such as RH (Soête et al. 1994). This has been confirmed using cells that represent a major niche for cystogenesis in vivo, such as muscle tissue (Ferreira da Silva et al. 2009b).

After 14 days of infection, cysts with a well-preserved ultrastructure indicative of cell viability were observed in the supernatant of infected cultures. These results are in accordance with Weiss et al. (1995), who detected free floating cyst-like structures released into the medium of tissue cultures within 3 days of infection. Thus, the CRFK line represent a potential cellular model for large scale cyst and bradyzoite production in vitro, which would allow a reduction in the number of animals used and/or replacement of animals by in vitro cultures.

The results of the novel use of epithelial cell lines in this study showed that they may contribute to our better understanding of the cell biology of Toxoplasma. The CRFK cell line has great potential as an alternative method to investigate the molecular aspects of $T$. gondii-feline cells interaction under controlled conditions. Altering the culture medium conditions by changing $\mathrm{pH}$ or using thermic shock may induce an increased rate of cystogenesis in these cultures. Because laboratory practices today require the adoption of the 3Rs (reuse, refinement and reduction) with regards to animals in research (Balls 2007), this approach could open a new field of research and gradually reduce the use of animals to obtain cysts and bradyzoites of T. gondii.

Acknowledgements. We are grateful to Sandra Maria de Oliveira Souza, Marielle Delfin Pereira and Genesio Lopes de Faria for their technical assistance and Dr. José Roberto Mineo from Immunoparasitology Laboratory, Federal University of Uberlândia, Minas Gerais, Brazil for providing anti-SAG-1 antibodies. This research was supported by grants from the Conselho Nacional de Desenvolvimento Científico e Tecnológico (CNPq), Fundação Carlos Chagas Filho de Amparo à Pesquisa do Estado do Rio de Janeiro (FAPERJ), Fundação Oswaldo Cruz (Programa Estratégico de Apoio à Pesquisa em Saúde - PAPES VI), Pronex - Programa de Apoio a Núcleos de Excelência - CNPq/ FAPERJ and the Instituto Oswaldo Cruz/Fiocruz.

\section{REFERENCES}

Balls M. 2007: Animal experimentation and the Three Rs: the need for hard heads and soft hearts and to confront the Three "I"s. Altern. Lab. Anim. 35: 547-548.

Black M.W., Boothroyd J.C. 2000: Lytic cycle of Toxoplasma gondii. Microbiol. Mol. Biol. Rev. 64: 607-623.

Cantin A., Woods D.E. 1930: Protection by antibiotics against myeloperoxidase-dependent cytotoxicity to lung epithelial cells in vitro. J. Clin. Invest. 91: 38-45.

Crandell R.A., Fabricant C.G., Nelson-rees W.A. 1973: Development, characterization, and viral susceptibility of a feline (Felis catus) renal cell line (CRFK). In Vitro 9: 176-185.

Darde M.L., Bouteille B., Leboutet M.J., Loubet A., PestreAlexandre M. 1989: Toxoplasma gondii: ultrastructural study of cystic formations observed in human fibroblast culture. Ann. Parasitol. Hum. Comp. 64: 403-411.

DuBEy J.P. 1973. Feline toxoplasmosis and coccidiosis: a survey of domiciled and stray cats. J. Am. Vet. Med. Assoc. 162: 873-877.

Dubey J.P. 1998: Advances in the life cycle of Toxoplasma gondii. Int. J. Parasitol. 28: 1019-1024.

Dubey J.P. 2006: Comparative infectivity of oocysts and bradyzoites of Toxoplasma gondii for intermediate (mice) and definitive (cats) hosts. Vet. Parasitol. 140: 69-75.
Dubey J.P., Frenkel, J.K. 1972: Cyst-induced toxoplasmosis in cats. J. Protozool. 19: 155-177.

Dubey J.P., Frenkel J.K. 1973: Experimental Toxoplasma infection in mice with strains producing oocysts. J. Parasitol. 59: 505-512.

Dubey J.P., Lindsay D.S., Speer C.A. 1998: Structures of Toxoplasma gondii tachyzoites, bradyzoites, and sporozoites and biology and development of tissue cysts. Clin. Microbiol. Rev. 11: 267-299.

Dubey J.P., Navarro I.T., Sreekumar C., Dahl E., Freire R.L., Kawabata HH, Vianna M.C., Kwok O.C., Shen S.K., ThulLiez P., Lehmann T. 2004: Toxoplasma gondii infections in cats from Parana, Brazil: seroprevalence, tissue distribution, and biologic and genetic characterization of isolates. J. Parasitol. 90: 721-726.

Dzierszinski F., Nishi, M., Ouko L., Roos D.S. 2004: Dynamics of Toxoplasma gondii differentiation. Eukaryot. Cell 3: 992-1003.

FERGUSON D.J. 2004: Use of molecular and ultrastructural markers to evaluate stage conversion of Toxoplasma gondii in both the intermediate and definitive host. Int. J. Parasitol. 34: 347-360. 
FERGUSON D.J. 2009: Toxoplasma gondii: 1908-2008, homage to Nicolle, Manceaux and Splendore. Mem. Inst. Oswaldo Cruz 104: 133-148.

Ferguson D.J., Hutchison W.M., Dunachie J.F., Simm J.C. 1974: Ultrastructural study of early stages of asexual multiplication and microgametogony of Toxoplasma gondii in the small intestine of the cat. Acta Pathol. Microbiol. Scand. B. Microbiol. Immunol. 82: 167-181.

Ferguson D.J., Hutchison W.M., Sirm J.C. 1975: The ultrastructural development of the macrogamete and formation of the oocyst wall of Toxoplasma gondii. Acta Pathol. Microbiol. Scand. B. 5: 491-505.

Ferreira da Silva M.F., Barbosa H.S., Gross U., Lüder C.G. 2008: Stress-related and spontaneous stage differentiation of Toxoplasma gondii. Mol. Biosyst. 4: 824-834.

Ferreira da Silva M.F., Rodrigues R.M., Andrade, E.F., Carvalho, L., Gross U., Lüder C.G., Barbosa H.S. 2009a: Spontaneous stage differentiation of mouse-virulent Toxoplasma gondii RH parasites in skeletal muscle cells: an ultrastructural evaluation. Mem. Inst. Oswaldo Cruz 140: 196-200.

Ferreira da Silva M.F., Takács A.C., Barbosa H.S., Gross U., LÜder C.G. 2009b: Primary skeletal muscle cells trigger spontaneous Toxoplasma gondii tachyzoite-to-bradyzoite conversion at higher rates than fibroblasts. Int. J. Med. Microbiol. 299: 281-288.

Fischer H.G., Nitzgen B., Reichmann G., Gross U., Hadding U. 1997: Host cells of Toxoplasma gondii encystation in infected primary culture from mouse brain. Parasitol. Res. 83: 637-641.

Flood P.P. 1975: Scanning electron microscope observations on the muscle innervation of Oikopleura dioica Fol (Appendicularia, Tunicata) with notes on the arrangement of connective tissue fibres. Cell Tissue Res. 164: 357-369.

Freyre A. 1995: Separation of Toxoplasma cysts from brain tissue and liberation of viable bradyzoites. J. Parasitol. 81: 1008-1010.

Guimarães E.V., Acquarone M., de Carvalho L., Barbosa H.S. 2007: Anionic sites on Toxoplasma gondii tissue cyst wall: expression, uptake and characterization. Micron 38: 651-658.

Guimarães E.V., de Carvalho L., Barbosa H.S. 2008: Primary culture of skeletal muscle cells as a model for studies of Toxoplasma gondii cystogenesis. J. Parasitol. 94: 72-83.

Hoff R.L., Dubey J.P., Behbehani A.M., Frenkel J.K. 1977: Toxoplasma gondii cysts in cell culture: new biologic evidence. J. Parasitol. 63: 1121-1124.

Hogan M.J., Yoneda C., Feeney L., Zweigart P., Lewis A. 1960: Morphology and culture of Toxoplasma. Arch. Ophthalmol. 64: 655-667.

Received 16 July 2013
Jones T.C., Bienz K.A., Erb P. 1986: In vitro cultivation of Toxoplasma gondii cysts in astrocytes in the presence of gamma interferon. Infect. Immun. 51: 147-156.

Lehmann T., Blackston C.R., Parmley S.F., Remington J.S., Dubey J.P. 2000: Strain typing of Toxoplasma gondii: comparison of antigen-coding and housekeeping genes. J. Parasitol. 86: 960-971.

Lindsay D.S., Blagburn B.L., Dubey J.P., Mason W.H. 1991: Prevalence and isolation of Toxoplasma gondii from whitetailed deer in Alabama. J. Parasitol. 77: 62-64.

Matsubayashi H., Akao S. 1963: Morphological studies on the development of the Toxoplasma cyst. Am. J. Trop. Med. Hyg. 12: $321-333$

McHugh T.D., Gbewonyo A., Johnson J.D., Holliman R.E., Butcher P.D. 1993: Development of an in vitro model of Toxoplasma gondii cyst formation. FEMS Microbiol. Lett. 114: 325-332.

Moura M.A., Amendoeira M.R., Barbosa H.S. 2009: Primary culture of intestinal epithelial cells as a potential model for Toxoplasma gondii enteric cycle studies. Mem. Inst. Oswaldo Cruz 104: 862-864.

Popiel I., Gold M.C., Воотн K.S. 1996. Quantification of Toxoplasma gondii bradyzoites. J. Parasitol. 82: 330-332.

Shimada K., O'Connor G.R., Yoneda C. 1974: Cyst formation by Toxoplasma gondii (RH strain) in vitro. The role of immunologic mechanisms. Arch. Ophthalmol. 92: 496-500.

SoÊte M., Camus D., Dubremetz J.F. 1994: Experimental induction of bradyzoite-specific antigen expression and cyst formation by the RH strain of Toxoplasma gondii in vitro. Exp. Parasitol. 78: 361-370.

Speer C.A., Dubey J.P. 2005: Ultrastructural differentiation of Toxoplasma gondii schizonts (types B to E) and gamonts in the intestines of cats fed bradyzoites. Int. J. Parasitol. 35: 193-206.

Weiss L.M., Kiм K. 2000: The development and biology of bradyzoites of Toxoplasma gondii. Front. Biosci. 5: 391-405.

Weiss L.M., Laplace D., Takvorian P.M., Tanowitz H.B., Cali A., Wittner M.A. 1995: A cell culture system for study of the development of Toxoplasma gondii bradyzoites. J. Eukaryot. Microbiol. 42: 150-157.

Zhang Y.W., Halonen S.K., Ma Y.F., Tanowtiz H.B., Weiss L.M. 2010: A purification method for enrichment of the Toxoplasma gondii cyst wall. J. Neuroparasitol. 1: 1-6.

Zhang Y.W., Halonen S.K., Ma Y.F., Wittner M., Weiss L.M. 2001: Initial characterization of CST1, a Toxoplasma gondii cyst wall glycoprotein. Infect. Immun. 69: 501-507.

Accepted 11 November 2013 